\title{
From basic raw material goods to cultural and environmental services: the Chinese bamboo sophistication path
}

\author{
Manuel Ruiz Pérez ${ }^{1}$, Lucas Gutierrez Rodriguez $^{1,2}$ Xiaosheng Yang $^{3}$, Jinzhong Xie $^{3}$ and Maoyi Fu ${ }^{3}$
}

\begin{abstract}
Bamboo has deep cultural and economic roots in China, the country with the largest bamboo resources in the world. Over the last three decades bamboo has evolved from a supply of raw material for basic goods into the material base of an increasingly diversified array of products and, more recently, into a potentially important source of cultural and environmental services. Based on a general literature review and the lessons learned from detailed case studies in different regions of China, we explored the changing roles of bamboo, and its effects on local economies and farmers' livelihood strategies. As the country develops and new economic activities continue to appear, bamboo production has shifted from a superior income-generating opportunity that largely benefited the better-off to a less attractive option left for those who have no other choice. The nature of the work has also changed, from families working directly on their bamboo plots to an emphasis on hired labor, with prosperous bamboo owners devoting most of their time to more lucrative activities. A similar process can be observed in bamboo processing in counties where previous industrial structures hinged around raw material harvests, but which have now entered into other secondary and tertiary industry activities. At the same time, bamboo has attracted new opportunities as a source of cultural, aesthetic, and leisure-related activities, as well as some potentially important climatic, watershed, and biodiversity functions. We analyze the complementarity between goods and services provided by bamboo and discuss some research issues and future trends that may help in overcoming these conflicts.
\end{abstract}

Key Words: bamboo culture; bamboo economy; bamboo farmers; bamboo forests; bamboo industry; bamboo plantations; bamboo tourism; China; cultural services; economic services; forestry; rural development; rural livelihoods

\section{INTRODUCTION}

\section{China, a fast-changing country}

In 1978, at the onset of the reform that resulted in one of the most dramatic changes in human history, China had a population of 963 million people of which $82 \%$ lived in rural areas. By 2011, 33 years later, the population was 1347.4 million; the urban population had exploded, resulting in a six-fold increase, while the rural population had decreased, both in absolute and relative terms, representing only $48.7 \%$ of the total population. During this period, the GDP multiplied by 19 in real terms with a sustained yearly increase of around $10 \%$ for most of that time (National Bureau of Statistics of China n.d., UNDP-China 2010).

In 1978 China was a very poor, rural country with hundreds of millions of peasants that constituted $70.5 \%$ of total labor and produced 28.2\% of GDP. By 2011 the country had become urbanized; primary industry comprised only $34.8 \%$ of total employment (about half of the prereform period), and its contribution to GDP had declined to just $10 \%$ (Fig. 1). It is worth emphasizing that while the secondary industry has maintained a relatively constant contribution to GDP (albeit with a significant increase in employment), the opposite change to that observed in primary industry has taken place in the tertiary industry; the latter nowadays accounts for a similar level of employment as agriculture but with a four-times larger contribution to GDP.

The opening up of China to the wider world has not only meant increased levels of production, consumption, and trade. It has also resulted in increased travel, not only in terms of foreign visitors to China but also Chinese travelling abroad. In 1990 China received 10.5 million tourists but by 2012 it had become the world's third-largest international tourist destination with some 57.7 million visitors (UNWTO 2013). More relevant to our bamboo world, China has also opened to itself with domestic tourism increasing from 524 million man-days in 1994 to 2.6 billion man-days in 2011 (National Bureau of Statistics of ChinaYearbook 2013). China's travel and tourism sector directly generated $2.6 \%$ of total GDP in 2012, reaching a 9.3\% share of GDP if we also include the indirect crossed-benefits (WTTC 2013). Moreover, Chinese society is becoming increasingly cosmopolitan and, as we shall see, this has also opened new opportunities to farmers in traditionally well-known bamboo areas.

China's rapid development poses a number of environmental, social, and political questions and challenges. What has made it possible? What effects has it had on rural areas? And more importantly with regards to this study, how are these changes reflected in the forestry and, in particular, the bamboo sectors? Here we will try to answer some of these questions based on two key premises: (1) that bamboo's attributes offer both material and cultural value to Chinese people (Zhao 2002, Yang et al. 2010); and (2) that farmers have economic expectations, and are shifting the focus of their activities in relation to the opportunity costs of their labor (Lanjow and Lanjouw 2001, Tian et al. 2011). We combine a general literature review, expert understanding, and our own long-term field research results. The latter, although spread in different provinces, focuses on Anji county, Zhejiang, which is in eastern China, southwest of Shanghai.

${ }^{1}$ Department of Ecology, Autonomous University of Madrid, ${ }^{2}$ Center for International Forestry Research, Indonesia, ${ }^{3}$ Research Institute of Subtropical Forestry, Chinese Academy of Forestry, China 
Fig. 1. Contribution to employment and GDP of primary, secondary, and tertiary industries in 1978 and 2011. The National Bureau of Statistics of China follows the International Standard Industrial Classification of all Economic Activities published by the UN Statistics Division (UNSTAT 2008). Primary refers to agriculture, forestry, animal husbandry, and fishery industries. Secondary refers to mining and quarrying, manufacturing, production and supply of electricity, water and gas, and construction industries. Tertiary refers to all other economic activities not included in the primary or secondary industries (see UNSTAT 2008 and National Bureau of Statistics of China for detailed descriptions). Source: based on China Statistical Yearbook (National Bureau of Statistics of China (several years)).

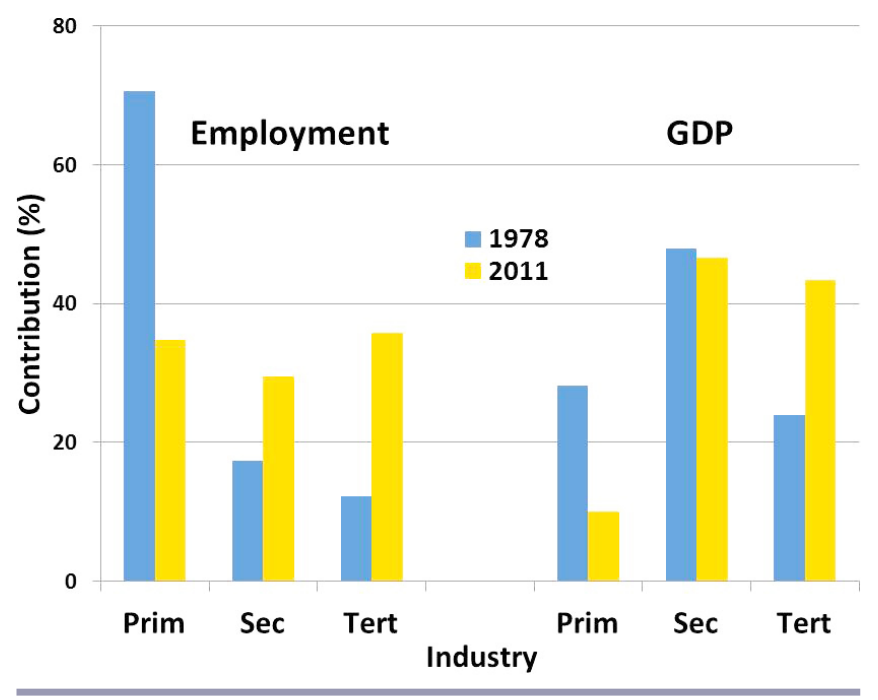

Dual roles of bamboo in Chinese culture: material and spiritual Bamboo is an important forest resource and has a major cultural role in Chinese society (Yang et al. 2010). Neolithic excavations of the Yangshao culture in Banpo, near Xi'An (Shaanxi 6800-3600 AC) and of the Hemodu culture in Yuyao (Zhejiang 3200-3000 AC) have showed that bamboo was already being used and represented with ideograms more than 5000 years ago $(\mathrm{Hu}$ and Hui 2002, Wang and Li 2006). New uses and increasingly complex bamboo-related technologies employed in tool making, housing, musical instruments, food, paper, irrigation systems, and different transporting devices and infrastructures were developed to cater to people's basic daily needs (Zou and Liang 2008).

In parallel with this "material culture", bamboo was increasingly incorporated into the religious, literary, artistic, and philosophical culture of ancient China. Thus, various cultural minorities of southern China have developed complex worship systems associated with it (Wang 2001). These belief systems stress the fast growth and strength of bamboo while using it as a totemic symbol of the source of life and even the origin of humans ( $z h u$ sheng ren). For these cultures bamboo is both a manifestation of social organization and its dynamic relation with the resource (Wang 2001).
Prior to the development of paper, bamboo slates were used in conjunction with other materials as a medium for writing. The Chinese character for bamboo-竹-can itself be clearly recognized on pottery from the Yangshao Culture (Yang et al. 2010). The first texts referring to bamboo represent its importance in people's life. Later came poems and other works dedicated to the contemplation of bamboo. Finally, the cultural elite started using bamboo to represent human feelings, idealized beauty, and moral values, underscoring the evolving relationship between bamboo and society (Zhao 2002). As a consequence of this longterm evolution, at the time of the Qing Dynasty (1616-1911 CE) the Kang Xi Dictionary records 960 bamboo-related characters (Yang et al. 2010).

$\mathrm{Su}$ (2013) attributes the rise of bamboo in Chinese culture to three threads. One thread is the literary technique of yongwu using different (usually natural) objects as a proxy to represent the author's inner self, to the extent that the ideogram of bamboo was frequently included in the poet's own name. A second thread is the entwining of moral values into the cultural meaning of bamboo. This occurred through the relating of bamboo's physical traits (straightness, flexibility, endurance, hollowness) to the moral virtues of honesty, loyalty, humility, and selflessness that characterized the junzi or morally superior person (similar to the concept of gentleman). A third thread is a retreating lifestyle that often meant living in close contact with bamboo in order to establish a spiritual connection with Nature. Through these different threads - by appealing to the individual characteristics of, as well as to the emotions inspired by, bamboo groves and forests-bamboo culture managed to incorporate Taoist, Buddhist and Confucian ideals. This laid the foundations for its unique place in Chinese culture as it became attractive to people from different ethnic and religious backgrounds and social strata. The poem Chanting Bamboo by Xu Tingjun (in Su 2013, page 72) epitomizes this extraordinary quality:

\section{It does not matter whether you are on a pavilion balcony or in a mountain forest. \\ [My] love for you is not just for the acres of shade you provide. \\ It is that you have integrity [jie] even before you sprout out of the earth; \\ When you surpass the clouds, you remain without ego.}

Cultural values are, therefore, superimposed upon and interact with bamboo's material properties, expanding them to establish a wide array of demands that can evolve as society develops. As such, the study of bamboo in China needs to be placed within the framework of this distinctive Bamboo Cultural Complex (Wang and $\mathrm{Li}$ 2006).

\section{Bamboo in the context of the Chinese forest transition}

China has traditionally been considered a country poorly endowed with forest resources. The available per capita forest area represents one-quarter of world averages and the standing timber volume only one-seventh (Forest Resources Administration 2010). Deforestation, a condition shared with many other areas of the world (MacNeill 2006, Kaplan et al. 2009, Bayon et al. 2012), has been the result of a long process of human expansion since the Neolithic, and has been further accentuated by subsequent demographic expansion, social crises, and wars 
between the 18th and 20th centuries. By 1900 forest cover had decreased to $16.7 \%$ (He et al. 2007).

At the time of the founding of the People's Republic of China there were only 109 million ha of forests which covered $11.4 \%$ of the country. In spite of pioneering reforestation programs during the 1950s, deforestation remained rampant with forest cover reaching its historical minimum of $8.9 \%$ during the Great Leap Forward (1959-1961) (Yin 1994, Ge et al. 2000). Forest barriers and new forest plantations were established during the 1960s and 1970 s with poor results due to bad practices and the social unrest of the Cultural Revolution period. Forest cover began a slow process of recovery but forest quality, especially of natural forests, continued to degrade (Wang and Chokkalingam 2006, Keeley and Zheng 2011).

The reforms initiated in 1978 placed a renewed emphasis on plantations and has been fundamental to improvements in forest cover and industry performance (Hyde et al. 2003), facilitating a "forest transition" in China (Gutierrez and Ruiz 2013) - although it was not until the 2000s when natural forests began a partial recovery with the implementation of the "six key forest programs", i.e., liu da linye zhongdian gongcheng (Zhou 2002). The latest forest inventory of 2004-2008 shows 195.5 million ha of forests, just above $20 \%$ of the national territory, and $13.720,8$ mill $\mathrm{m}^{3}$ of standing volume, a remarkable recovery from the situation 50 years ago.

What has been the trajectory of bamboo throughout the tumultuous history of Chinese forests?

The country, rich in bamboo species, has the world's largest bamboo surface area and highest levels of production. Since the creation of the Bamboo Chart by Dai Kaizhi (Jin Dynasty, 317420 A.D.) which described 61 species (considered the first world's monograph on bamboo), around 500 species distributed in 39 genera have been identified (Zhu et al. 1994). The long history of bamboo cultivation has resulted in a mixed gradient ranging from wild, naturally occurring bamboo forests to intensively managed monoculture plantations. Moso bamboo (Phyllostachys edulis) is the most common plantation species, although other species, including a number of sympodial bamboos associated with a fastgrowing and diversified demand (Ruiz Perez et al. 2009), are also grown.

Bamboo has many contradictory features. It is strong and hard, but also flexible, and it is elegant and spiritual, yet capable of serving as raw material for hundreds of different products and processes. Taxonomically, it is a grass that grows to the heights of a tree and has timber-like properties. Likewise, it also shares qualities of timber and economic tree forests. The main product, bamboo culms, is a substitute for timber and shares some of the latter's market features. At the same time, a fast-growing, short rotational cycle offers regular (yearly or biennial) harvests similar to cash crops. This has contributed to bamboo playing a special role in rural economies and farmers' livelihoods, as we shall explore in the following sections.

Some of these unique features may help explain why bamboo seems to have avoided the ups and downs faced by other Chinese forests during the second part of the $20^{\text {th }}$ century. We lack suitable data to analyze what happened to naturally occurring bamboo forests, but it is plausible that they may have followed a similar path of degradation to that of other natural forests. This is a potentially interesting research subject that to our knowledge has not been comprehensively explored. However, total bamboo area (natural forests and plantations) has maintained a steady increase over the past 50 years, in contrast to the severe deforestation experienced in the late 1950s and 1960s. Similarly, bamboo culm production has continued to increase steadily over the same period, having partially helped to cushion the impact of the decrease in timber production experienced for nearly a decade in the whole of China as a result of the 1998 logging ban (Figs. 2 and 3). Bamboo therefore seems to have fared better in the turmoil of the 1960s and 1970s than other type of forests, vindicating once again the widely held perceptions of its adaptive and flexible nature.

Fig. 2. Evolution of bamboo total area in China (National Bureau of Statistics of China, several years).

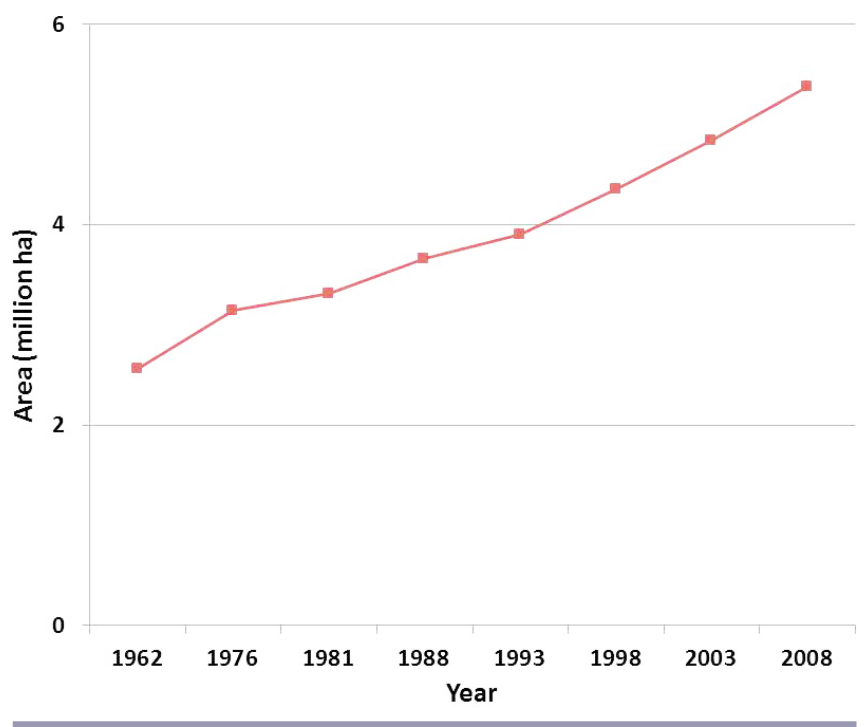

Fig. 3. Evolution of bamboo culm and shoot production in China (National Bureau of Statistics of China, several years).

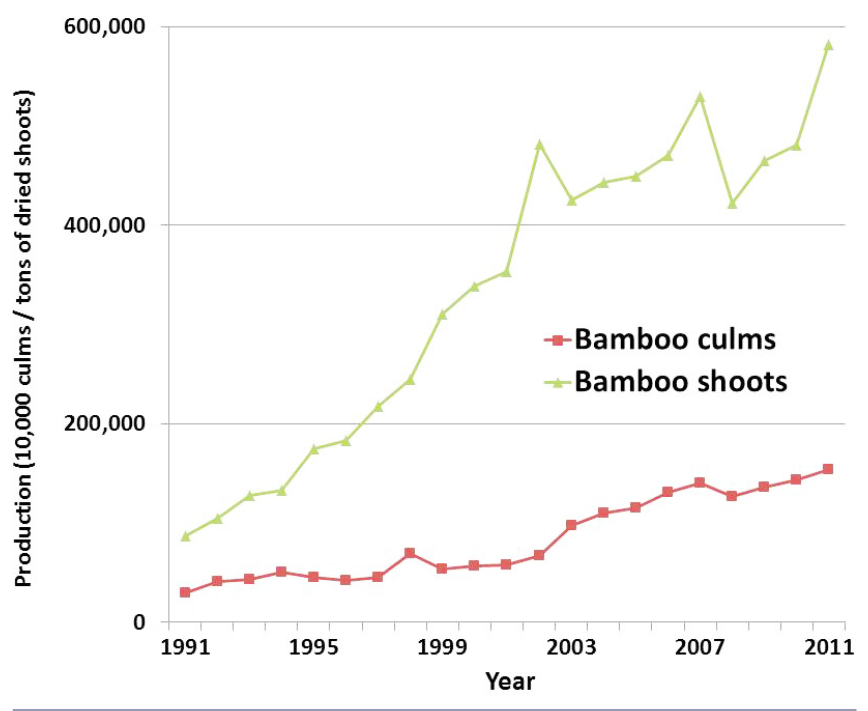




\section{ECONOMIC AND ENVIRONMENTAL ROLES OF BAMBOO}

\section{Bamboo: the "poor man's timber" or an economic opportunity for the better-off?}

The conventional view of bamboo portrays it as the "poor man's timber" (Rao et al. 1987) or, to allow for the modern concern of climate change, the "poor man's carbon sink" (Lobovikov et al. 2009). According to this view, bamboo serves as an option that allows the poor to thrive, eventually helping to facilitate poverty mitigation and elimination. The evidence for this hypothesis is the frequent higher contribution of bamboo to household economy in poorer households (Hogarth et al. 2013) and the possibility to climb up the social ladder and move from lower to higher income groups through bamboo cultivation (Kant and Chiu 2000).

A more nuanced view would also need to consider bamboo dynamism and the changing opportunities that the past three decades of impressive development have offered to Chinese farmers (Tian et al. 2011). An earlier study showed that in the mid 1990s, bamboo in Anji County, Zhejiang, was relatively more important for the middle income group of farmers, although the richest farmers were still generating more bamboo-based income in absolute terms (Ruiz Perez et al. 1999). We also suggested the growing role played by off-farm income in rural economies, something that was being postulated at the time for other areas and that is nowadays broadly acknowledged (Lanjouw and Lanjouw 2001, Haggblade et al. 2002, Reardon et al. 2007). This study led us to three key questions: When is bamboo a good opportunity for farmers? Is there a point when they would be interested in shifting to a more lucrative activity? And if so, what role should bamboo play in this transition?

To answer them we followed a complementary, two-pronged approach, linking the relative level of development of the village or county and the income-generating opportunities available. Using a cross-sectional study in six counties placed in three provinces along an east-west gradient of development, we showed that the role of bamboo in farmers' livelihoods changed depending on the level of development and on the off-farm opportunities available (Ruiz Perez et al. 2003, 2004). In the most developed counties, with higher per capita income and more economic opportunities, bamboo was more important for the poorest farmers; in least developed counties, bamboo was more important for those in the middle and high income categories. Interestingly, in poor counties and provinces, bamboo industry wages were close to average provincial-level industry wages, whereas in richer counties and provinces, bamboo industry wages lagged behind average provincial level wages (Fig. 4). As rural areas developed, not only bamboo cultivation but also the associated bamboo processing industries lost ground in terms of relative income and salaries.

At the same time, we used longitudinal time series in Daxi village of Anji county (a densely forested village where bamboo provides the main forest cover) to study the precise change that was taking place. Daxi is a very isolated, mountain village that depended on forest income (bamboo, hickory, and tea) until the construction of a large hydro-electric dam in the early 1990s improved transportation and offered new income opportunities through construction and the provision of lodgings for the workers that came to the site from outside the local community. This brought about dramatic changes to the village. Agriculture income maintained the same declining trend that had been observed since 1973, at the time of the first data available. Forestry, which had been the core economic activity - representing around two-thirds of total village income before the construction of the dam (mainly due to bamboo, itself contributing to around two-thirds of total forest income) - saw a sharp decline. Off-farm income then began to fill the gaps left by agriculture and forestry (Gutierrez et al. 2009, Fig. 5). Thus, it became apparent that new income sources were expanding the development options of the village that had previously relied on bamboo. Were these new opportunities being seized equally by all farmers? Was the relative weight of bamboo in farmers' economies changing for different income categories?

Fig. 4. Ratio of bamboo industry to average provincial industry wages, in relation to the county's per capita income (modified from Ruiz Perez et al. 2004).

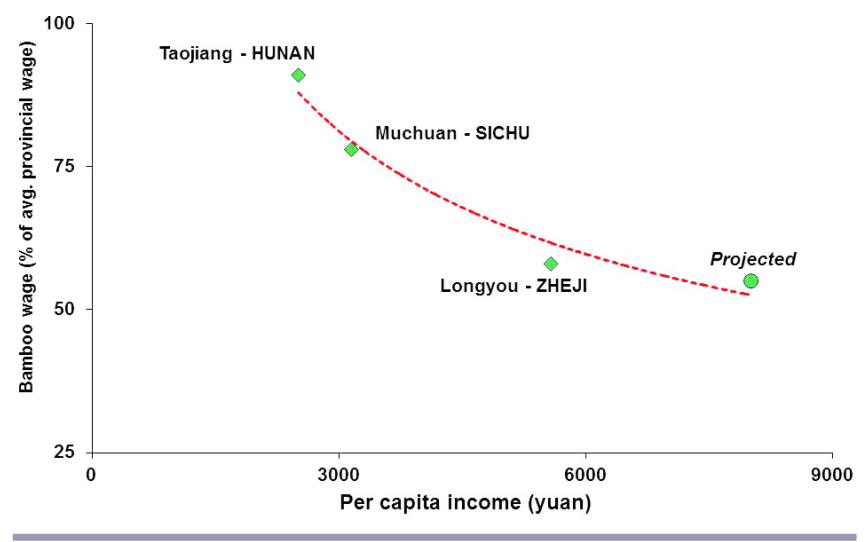

Fig. 5. Changes in income from agriculture, forestry, and offfarm activities in Daxi village, Anji, Zhejiang, 1973 to 2006 (modified from Gutierrez et al. 2009, based on unpublished statistics obtained from the Daxi village's handwritten notebooks).

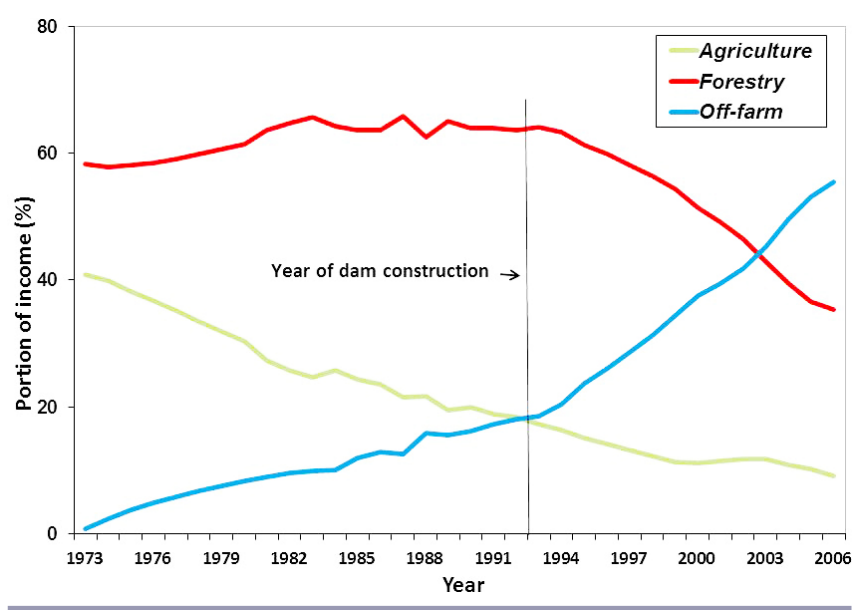

We were fortunate that Daxi had also long been used as a reference village in the yearly national rural population economic surveys. This permitted a detailed assessment of income structures and 
the changing role of forests, and specifically of bamboo, by comparing previous farmers' income data (Gutierrez et al. 2009) with our own survey conducted in 2006. As Fig. 6 shows, bamboo was in both relative and absolute terms more important for the better-off income groups before the construction of the dam, indicating that this was the most lucrative opportunity for them at that time. By 2005, however, bamboo had reduced its relative weight in all income categories (in concordance with the aggregated village data discussed above) and, more significantly, its role had changed, becoming more important for the poorest income category of farmers. Bamboo was no longer the best available income opportunity; hence, it became relatively more important to the low-income farmers. Unable to benefit from the new economic options, poor farmers were tied to bamboo as their main source of income, i.e., it was twice as important to them in relative terms than to the high income group.

Fig. 6. Relative contribution of bamboo to household income for the three income tertile groups: 1990 vs. 2005 (unpublished statistics for 1990 obtained from the Daxi village's handwritten notebooks; statistics for 2005 from Gutierrez et al 2009).

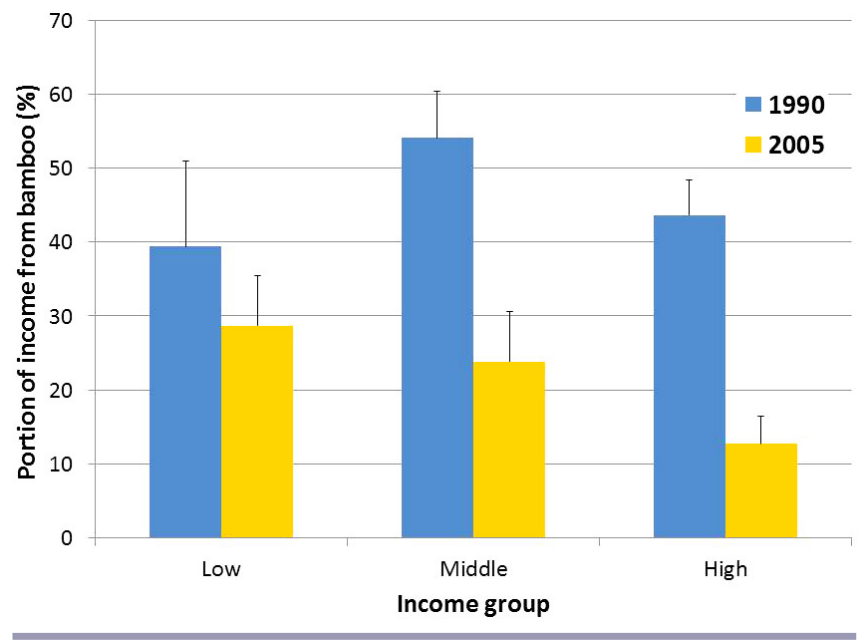

Given the egalitarian nature of the forest contract system, wealthier farmers kept their bamboo plots and were able to obtain similar or even higher incomes from them than poor farmers. However, the opportunity cost of labor for middle and high income farmers meant that they were more interested in employing it in more lucrative activities, frequently hiring poor farmers from Daxi and other villages as laborers to work their bamboo plots. Chen (2010) and Tian et al. (2011) have found similar responses by farmers in relation to their agricultural crops.

\section{New economic roles for bamboo}

The conclusions from cross-sectional and longitudinal studies pointed in the same direction and were in line with what could be predicted by economic theory: the most dynamic and entrepreneurial farmers were spearheading local innovation (Feder et al. 1985) and benefiting from off-farm economic opportunities (Lanjouw and Lanjouw 2001) while adjusting land use and labor allocation by renting land or hiring workers (Tian et al. 2011). In early development stages, when the primary industry was vital for employment and GDP, bamboo plantations and associated industry were a greater economic opportunity that attracted innovative farmers. As the country developed and the primary industry reduced its contribution to employment and GDP, bamboo was no longer a superior opportunity, leading to a reduction in its relative weight and giving way to more lucrative activities. So, what were these new opportunities and what was the new role that bamboo took on?

In our case study, during the 1990s they related to construction (dam, roads, and new houses), bamboo processing, and trade. In the 2000s a new opportunity linked to tourism emerged. Anji county has become a famous tourist destination, mainly from the Hangzhou-Shanghai-Nanjing triangle. Tourism has experienced an spectacular climb from just 150,000 tourists and $0.4 \%$ of total county GDP in 1996 to 5,440,000 tourists and $13.8 \%$ of GDP in 2009 (Gutierrez et al. 2011). Daxi village's outstanding mountain forest scenery (with bamboo as a central part of it) has been responsible for attracting a significant proportion of tourism to Anji. Based on our 2007 survey, tourism represented 27\% of total income, being the best off-farm income opportunity in Daxi. The young, more dynamic generation is benefiting the most with many "farmer rural home" hostels (nongjiale) built in the past decade. Similar situations created by an increasing demand for rural tourism are also occurring in other regions of China (Gao et al. 2009) and abroad (Fontana and Paciello 2009).

Again, bamboo has played a major role in encouraging this influx of tourists. A survey of Daxi visitors indicated that bamboo was the main known feature and a major attraction, with $93 \%$ of interviewees acknowledging that they had a pre-existing knowledge of beautiful bamboo scenery before arriving. Obviously, bamboo is not the only reason that people visit the area, and Anji's fame as a bamboo county may not be replicated everywhere. The point, however, is that this new opportunity is deeply rooted in the bamboo culture (of both farmers and visitors) of the region, going beyond the material output of the primary industry and into the services of the tertiary industry. As the Chinese economy progresses, the trend will be consolidated, pointing towards an important future economic avenue for bamboo farmers. At this point, it is worth remembering that the tourist sector is expected to grow faster than the wider Chinese economy in this decade (WTTC 2013).

New economic options change over place and time and we do not have a sufficiently large sample to extrapolate our detailed results to the whole of China. However, there is enough evidence to show that bamboo-based tourism was already developing in different regions in the 1990s and has continued its exponential expansion. Interestingly, bamboo has also attracted the attention of Western travelers in China, as evidenced by the numerous references to bamboo gardens, sceneries, and homes made by Cumming in his travel memoirs cited by Wang (2003).

In 1996 the State Forest Administration officially named the Ten Bamboo Home Counties based on the extent of their bamboo resources, the associated industry and the cultural value placed on bamboo in the county's traditions. Anji was one of these first Ten Bamboo Counties. The purpose was to establish tourist attraction poles that would disseminate the "immaterial" (spiritual) values associated to the Bamboo Cultural Complex (Wang and Li 2006). In 2007 the list was extended to 30 counties in 10 provinces (Anhui, Fujian, Guangdong, Guangxi, Guizhou, Hubei, Hunan, Jiangxi, Sichuan, and Zhejiang). Bamboo-based 
ecotourism continues to spread across the mountainous regions

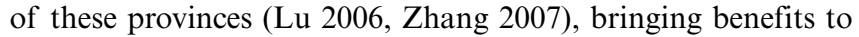
farmers similar to those we observed in Anji (Hu and Hui 2002). Visiting bamboo landscapes, museums, gardens, and homes represents a new resource (Guan 2003) and has become part of the package offered by numerous Chinese tour operators, as exemplified by this excerpt from one operator:

The Bamboo Sea, one of the most beautiful land of
happiness given by the nature, with many cultural relics
and historic sites screened by green bamboo, is a fresh
and clear back garden of Yibin City. A tour to the
beautifulandelegant Bamboo Sea is a tour to the splendid
bamboo culture of long history, a tour more mysterious
and interesting, far from the mortal world.
[From: http://www.chinayak.com/Panda/Attractions-
around-Chengdu/Bamboo-Sea.html]

As is frequently the case, new opportunities also bring new problems and, in the case of Anji (and, again, most likely in many other counties that offer scenic bamboo resources), large-scale tourism has already increased environmental pressures. This fact is well acknowledged by Anji authorities who recognize an unsustainable increase of waste and water pollution associated with a huge increase in urban development (Tianhuangping Tourist Reception Centre 2006). As an example, Daxi village has increased its urban space 4.8 times between 1988 and 2005 (Gutierrezet al. 2011). The need to carefully balance new demands and their environmental costs is clearly of the utmost importance here.

Forest tenure and income equality: is there anything special about bamboo?

The land reform launched with the Household Responsibility System (jiating lianchan chengbao zeren zhi) has been one of the cornerstones of China's development (Nolan 1983, Lin 1987). Its extension to forests through a Contract Responsibility System (shengchan chengbao zeren zhi) found a number of difficulties associated with the specific nature of forests, namely the long rotation, landscape persistence, and high environmental value. In the early stages, with farmers doubting that the policy would be maintained, some forests and plantations were cut and the timber was sold to obtain short-term benefits, leading to an estimated loss of over 1 million ha of forest in the southern collective forest region (Song et al. 1997, Liu 2001). However, the authorities reacted quickly to address the issue. In the absence of the appropriate data, we would hypothesize that the peculiarities of bamboo plantations preserved them from the destruction seen in other forests during this period. This again could be an interesting research topic.

A more insidious problem was the attempt to maintain the original egalitarian nature of land reform under changing demographic conditions that inevitably led to changing the per capita land allowance. Different solutions were found for the agricultural sector that in the early stages focused on periodic land reallocations, but these proved to be more difficult for forests, again due to long-term rotation, investment recovery, and convenience of unified management. An alternative option has been to establish forest shareholding cooperatives (linye gufen hezuo zhi) that contract the land and share the benefits with their members (Kong and Liu 2000, Song et al. 1997). The system focuses on timber production forests or plantations, offering a stable and unified forest management that avoids the fragmentation typical of the Contract Responsibility System (Kang et al. 2010).

Again, the specificities of bamboo plantations may demand other alternatives. Gutierrez et al. (2013) have illustrated an interesting option established in Anji, based on a compensation scheme between families at different demographic stages. We believe that other systems trying to combine an egalitarian land distribution with demographic trends and the advantages of standard management must have been developed in different regions of China, although to our knowledge no systematic comparison of how the bamboo Contract Responsibility System developed has been conducted.

The recent trends in land regulation in China may render these systems obsolete. However, aside from the academic interest, we believe that conducting such a China-wide tenure-arrangements study for bamboo could prove important because the Contract Responsibility System has been crucial for maintaining one of the most interesting features of bamboo in rural development: its highly egalitarian nature. As demonstrated by Kant and Chiu (2000), Ruiz Perez et al. (2004), Gutierrez et al. (2009), and Hogarth et al. (2013), bamboo income shows relatively low Gini coefficients (a commonly used index measuring the income distribution in a population, which ranges from 0 (maximum equality) to 1 (maximum inequality), Gastwirth 1972)), thus indicating a fairly egalitarian economic activity (Table 1). In rural areas with a strong tradition of bamboo plantations, these offer a partial buffer against the growing income disparities that are currently considered one of the key issues facing China. Clearly bamboo's role in solving this huge problem may be rather limited. However it is rooted in the ideas of egalitarian land distribution and the ability to offer regular income to farmers at different points on the income ladder.

Table 1. Changes in Gini coefficients for main sources of income in Daxi village between 1990 and 2005 (unpublished statistics for 1990 obtained from the Daxi village's handwritten notebooks; statistics for 2005 from Gutierrez et al. 2009).

\begin{tabular}{lcc}
\hline \hline Income & Gini 1990 & Gini 2005 \\
\hline Bamboo & 0.26 & 0.32 \\
Hickory & 0.47 & 0.56 \\
Tea & 0.46 & 0.74 \\
Off-farm & 0.53 & 0.76 \\
& & \\
\hline
\end{tabular}

\section{Environmental values of bamboo: the light and the shade}

Naturally occurring bamboo forests, like any other natural forest, tend to have important environmental value associated with a high biodiversity and biomass, soil retention, and hydrological cycle control. Indeed, the world-famous pandas live in natural bamboo forests. However, most of China's bamboo area corresponds to plantations, which tend to be intensively managed monocultures. What are their environmental shortcomings? To what extent do they contribute to global forests' environmental values? 
Numerous authors have studied the issue (Zhou et al. 2005, Xie 2006, Yan et al. 2008, Ruiz Perez et al. 2009; Yang et al. 2010). Plantations in general have less diversity and biomass, allied to a higher number of disturbances than mature natural forests due to management and extraction ( Xu 2011). In this regard, bamboo plantations are no exception. Expanding bamboo plantations at the expense of natural forests was not uncommon in the 1980s and 1990s, which naturally affected biodiversity, soil, and hydrological functions (Ruiz Pérez et al. 2001). However, following the logging ban of 1998 the loss of natural forests has been gradually halted.

Although natural forests have a higher tree alpha diversity than bamboo plantations, this is partly compensated for by greater diversity in the shrub and herbaceous layers of the latter (Xie 2006). Indeed, extensive bamboo can compare favorably with timber plantations like Chinese fir (Cunninghamia lanceolata), although its biodiversity value diminishes significantly with intensive management. Moreover, extensive bamboo plantations tend to have high beta (between plots) diversity, due to variations in management that are expressed at the herbaceous and shrub levels (Xie 2005, Gutierrez et al. 2012). This contributes to the high scenic and cultural values of many bamboo areas, which are important features for attracting rural tourism.

At the same time, many bamboo species tend to be very fastgrowing and thus demonstrate excellent performance in carbon sequestration. Projecting the observed changes in $\mathrm{C}$ stocked in China's bamboo forests and plantations, Chen et al. (2009) estimate a potential growth of $40 \%$ by 2050 . This again may contribute to generating income for bamboo farmers as part of carbon emissions compensation schemes, as already noticed by some authors (Lobovikov et al. 2009).

Once more we find trade-offs between intensively managed plantations with faster growth and higher biomass and other environmental values like biodiversity, soil disturbance, levels of agrochemicals, and water quality (Buckingham 2009, Ruiz Perez et al. 2009). Thus, while Zhou et al. (2005) and Xie (2006) stress that bamboo plantations maintain a good level of soil coverage and biomass, Yan et al. (2008) found significant reduction in soil nitrogen mineralization and nitrification in bamboo and other plantations compared with evergreen broad-leaved forests, suggesting a negative impact on soil fertility. This is compounded by a reduction in soil microbial activity found in intensively managed bamboo plantations (Xu et al. 2008). Likewise, while fertilization and mulching of intensively managed bamboo plantations may increase soil carbon pools ( $\mathrm{Li}$ et al. 2010), they also increase seasonal soil $\mathrm{CO}_{2}$ efflux, thereby reducing their carbon sequestration potential (Liu et al. 2011).

The environmental pros and cons of bamboo plantations should be assessed in relation to their management and level of intensification, and in the context of other (current or potential) alternative land uses. Low-input, traditionally managed plantations are environmentally friendlier than intensive ones. Bearing this in mind, it is nevertheless clear that their environmental value will be increasingly important and could play a significant role in guiding farmers' management practices and bamboo-related income, as suggested by pioneer policies aimed at encouraging a de-intensification of bamboo plantations (Ruiz Pérez et al. 2001) as well as by the establishment of bamboo certification schemes. Likewise, some polluting bamboo- processing industries have been forced to upgrade or close down, as epitomized by the case of the bamboo paper industry in Muchuan (Sichuan). In this respect, a systematic review of environmental impacts of bamboo production and of the various types of payments for environmental services as applied to bamboo plantations in China also seems to be a much-needed and promising research topic.

\section{CONCLUDING REMARKS}

Bamboo plantations fall somewhere between natural forests and other agrarian uses - closer to forests in some environmental and raw material output respects, yet closer to economic tree crops in income, labor, tenure, and other socioeconomic considerations in other respects. Unsurprisingly, they meet the standard economic theory of farmers' expectations in relation to the opportunity costs of factors of production: seized by the wealthier when they are a good opportunity and passing the flag down to low-income farmers when better opportunities appear.

A balanced view should find an equilibrium between unreasonable expectations of bamboo-based wealth and social promotion on one hand, and the stereotype of being poor man's timber on the other, and between an ecologically mature natural forest and an environmentally disruptive intensive plantation or crop. Bamboo has played a significant role in China's rural development, and its continued expansion proves that it will be here for a long time. Yet, having fulfilled that foundational role, new openings will have to be worked out in order to realize its full potential. Building on the unique Bamboo Cultural Complex of China, a dynamic relationship between the physical and immaterial values of bamboo is gradually developing with increasingly sophisticated uses. Thus, the material output of the bamboo sector will remain and will have to be continually reinforced, but additional recreational, cultural, and environmental opportunities have also emerged.

Helping to seize them should be an important part of any new forest policies that are increasingly aimed at promoting cultural, recreational, and environmental values. Bamboo could represent an excellent example of a much-needed compromise between production, culture, and conservation in rural China.

Responses to this article can be read online at: http://www.ecologyandsociety.org/issues/responses. $\mathrm{php} / 6701$

\section{Acknowledgments:}

We sincerely appreciate the constructive and useful comments provided by two anonymous reviewers.

\section{LITERATURE CITED}

Bayon, G., B. Dennielou, J. Etoubleau, E. Ponzevera, S. Toucanne, and S. Bermell. 2012. Intensifying weathering and land use in Iron Age Central Africa. Science 335(6073):1219-1222. http://dx.doi. org/10.1126/science. 1215400

Buckingham, K. 2009. Deep roots in culture, shallow roots in nature: identifying sustainable bamboo management challenges for China and the implications for multidisciplinary research. 
International Association of Agricultural Economists Conference, Beijing, 16-22th August 2009.

Chen, X., X. Zhang, Y. Zhang, T. Booth, and X. He. 2009. Changes of carbon stocks in bamboo stands in China during 100 years. Forest Ecology and Management 258(7):1489-1496.

Chen, Y. 2010. Agricultural land use responses to the rising labor opportunity cost in Sui County, China. Chinese Journal of Population Resources and Environment 8(4):10-18.

Feder, G., R. E. Just, and D. Zilberman. 1985. Adoption of agricultural innovations in developing countries: a survey. Economic Development and Cultural Change 33:255-298. http:// dx.doi.org/10.1086/451461

Fontana, M., and C. Paciello. 2009. Gender dimensions of rural and agricultural employment: differentiated pathways out of poverty - a global perspective. Paper presented at the FAO-IFADILO Workshop on Gaps, Trends and Current Research in Gender Dimensions of Agricultural and Rural Employment: Differentiated Pathways Out of Poverty, Rome, Italy, 31 March-2 April.

Forest Resources Administration-PRC's Ministry of Forestry (Guojia linyeju senlin ziyuan guanglisi). 2010. National forest resources inventory and general situation of forest resources in the PRC [Diqici quanguo senlin ziyuan qingcha ji senlin ziyuan zhuangkuang]. Linye ziyuan guangli [Forest Resources Management] 1:1-8. (In Chinese)

Gao, S., S. Huang, and Y. Huang. 2009. Rural tourism development in China. International Journal of Tourism Research 11:439-450. http://dx.doi.org/10.1002/jtr.712

Gastwirth, J. L. 1972. The estimation of the Lorentz curve and the Gini index. The Review of Economics and Statistics 54:306-316. http://dx.doi.org/10.2307/1937992

Ge, Q., M. Zhao, and J. Zheng. 2000. Landuse change of China during the 20th century (Ershi shiji zhongguo tudi liyong bianhua yanjiu). Dili xuebao [Journal of Geography] 55(6):698-706. (In Chinese)

Guan, C. 2003. Bamboo landscape resources in China. Zhongguo de zhu jingguan ziyuan. Zhuzi yanjiu huikan [Journal of Bamboo Research] 22(2):73-78. (In Chinese)

Gutiérrez Rodríguez, L., M. Fu, Geriletu, Z. Li, M. Ruiz Pérez, J. Xie, X. Yang, and B. Zhou. 2012. Ecological functionality of Phyllostachys edulis (Moso Bamboo) within a subtropical forest community in eastern China - a quantitative analysis of biodiversity, biomass and coverage parameters at Daxi village, Anji County. $8^{\text {th }}$ China Bamboo Congress, Zhuji city (Zhejiang), 22-24th November 2012.

Gutiérrez Rodríguez, L., and M. Ruiz Pérez. 2013. Recent changes in Chinese forestry seen through the lens of forest transition theory. International Forestry Review 15(4):456-470.

Gutiérrez Rodríguez, L., M. Ruiz Pérez, X. Yang, and Geriletu. 2011. From farm to rural hostel: new opportunities and challenges associated with tourism expansion in Daxi, a village in Anji County, Zhejiang, China. Sustainability 3:306-321. http://dx.doi. org/10.3390/su3010306
Gutiérrez Rodríguez, L., M. Ruiz Pérez, X. Yang, M. Fu, Geriletu, and D. Wu. 2009. Changing contribution of forests to livelihoods: evidence from Daxi Village, Zhejiang Province, China. International Forestry Review 11(3):319-330.

Gutiérrez Rodríguez, L., M. Ruiz Pérez, X. Yang, Geriletu., B. Belcher, B. Zhou, and Z. Li. 2013. Maintaining the contract responsibility system of forest land distribution in China: evidence from a novel financial compensation scheme in Daxi Village of Anji County, Zhejiang. Land Use Policy 30:863-872. http://dx.doi.org/10.1016/j.landusepol.2012.06.004

Haggblade, S., P. Hazell, and T. Reardon. 2002. Strategies for stimulating poverty-alleviating growth in the rural nonfarm economy in developing countries. EPTD Discussion Paper \#92. World Bank, Washington, D.C., USA.

He, F., Q. Ge, J. Dai, and S. Lin. 2007. Quantitative analysis on forest dynamics of China in recent 300 years (Jin sanbainian lai zhongguo senlin de bianqian). Dilixuebao [Journal of Geography] 62(1):30-40. (In Chinese)

Hogarth, N. J., B. Belcher, B. Campbell, and N. Stacey. 2013. The role of forest-related income in household economies and rural livelihoods in the border-region of southern China. World Development 43:111-123. http://dx.doi.org/10.1016/j.worlddev.2012.10.010

Hu, J., and C. Hui. 2002. Summary of bamboo culture and bamboo culture tourism in China (Zhongguo zhu wenhua ji zhu wenhua lvyou yanjiu de xianzhuang he zhanwang). Zhuzi yanjiu huikan [Journal of Bamboo Research] 21(3):66-75. (In Chinese)

Hyde, W. F., B. Belcher, and J. Xu, editors. 2003. China's forests: global lessons from market reforms. Resources for the Future, Washington D.C. \& CIFOR, Bogor, Indonesia.

Kang, Y., L. Gao, and Y. Li. 2010. Study review on forestry shareholding cooperation (linye gufen hezuo yanjiu zhongshu). Anhui nongye kexue [Journal of Anhui Agriculture] 38 (31):17890-17891. (In Chinese)

Kant, S., and M. Chiu. 2000. Bamboo sector reforms and the local economy of Linan County, Zhejiang Province, People's Republic of China. Forest Policy and Economics 1(3-4):283-299. http://dx.doi.org/10.1016/S1389-9341(00)00021-6

Kaplan, J. O., K. M. Krumhardt, and N. Zimmerman. 2009. The prehistoric and preindustrial deforestation of Europe. Quaternary Science Reviews 28:3016-3034. http://dx.doi.org/10.1016/j. quascirev.2009.09.028

Keeley, J., and Y. Zheng (editors). 2011. Green China: Chinese insights on environment and development. International Institute for Environment and Development (IIED), London, UK.

Kong, M., and C. Liu. 2000. An investigation on the development of the forest shareholding system in Sanming, Fujian province (fujiansheng sanmingshi linye gufen hezuo zhi fazhan yanjiu). Linye jingji [Forestry Economics] 1:7-20. (In Chinese)

Lanjouw, J. O., and P. Lanjouw. 2001. The rural non-farm sector: issues and evidence from developing countries. Agricultural Economics 26:1-23. http://dx.doi.org/10.1111/j.1574-0862.2001. tb00051.x 
Li, Y., P. Jiang, S. C. Chang, J. Wu, and L. Lin. 2010. Organic mulch and fertilization affect soil carbon pools and forms under intensively managed bamboo (Phyllostachys praecox) forests in southeast China. Journal of Soils and Sediments 10(4):739-747. http://dx.doi.org/10.1007/s11368-010-0188-4

Lin, J. Y. F. 1987. The household responsibility system reform in China: a peasant's institutional choice. American Journal of Agricultural Economics 69(2):410-415.

Liu, D. C. 2001. Tenure management of non-state forests in China since 1950: a historical review. Environmental History 6 (2):239-263.

Liu, J., P. Jiang, H. Wang, G. Zhou, J. Wu, F. Yang, and X. Qian. 2011. Seasonal soil $\mathrm{CO}_{2}$ efflux dynamics after land use change from a natural forest to Moso bamboo plantations in subtropical China. Forest Ecology and Management 262(6):1131-1137.

Lobovikov, M., Y. P. Lou, D. Schoene, and R. Widenoja. 2009. The poor man's carbon sink: bamboo in climate change and poverty alleviation. INBAR-FAO, Rome, Italy.

Lu, S. 2006. Theme tourism booming in China-research on bamboo culture in ethnic minority regions, Yunnan Province. In Proceedings of the 2006 International Conference on Management Science and Engineering 121-125, 2006, Wuhan, Hubei, China. Orient Academic Forum, New South Wales, Australia.

McNeill, J. R. 2006. China's environmental history in world perspective. Pages 31-52 in M. Elvin and T. Liu, editors, Sediments of time. Environment and society in Chinese history. Cambridge University Press, Cambridge, U. K.

National Bureau of Statistics of China. (several years). China statistical yearbook. China Statistics Press, Beijing, China.

Nolan, P. 1983. De-collectivisation of agriculture in China, 1979-82: a long-term perspective. Economic and Political Weekly 18(32):1395-1418.

Rao, A. N., G. Dhanarajan, and C. B. Sastry, editors. 1987. Recent research on bamboos - proceedings of the 2 ndinternational bamboo workshop, Hangzhou, China, 6-14 1985. Chinese Academy of Forestry, Beijing, China and International Development Research Centre, Ottawa, Canada.

Reardon, T., K. Stamoulis, and P. Pingali. 2007. Rural nonfarm employment in developing countries in an era of globalization. Journal of Agricultural Economics 37:173-184. http://dx.doi. org/10.1111/j.1574-0862.2007.00243.x

Ruiz Pérez, M., B. Belcher, M. Fu, and X. Yang. 2003. Forestry, poverty and rural development: perspectives from the bamboo subsector. Pages 151-176 in W. F. Hyde, B. Belcher, and J. Xu, editors. China's forests: global lessons from market reforms. Resources for the Future, Washington D.C. \& CIFOR, Bogor, Indonesia.

Ruiz Pérez, M., B. Belcher, M. Fu, and X. Yang. 2004. Looking through the bamboo curtain: an analysis of the changing role of forest and farm income in rural livelihoods in China. International Forestry Review 6 (3-4):306-316.

Ruiz Pérez, M., M. Fu, X. Yang, and B. Belcher. 2001. Bamboo forestry in China: toward environmentally friendly expansion. Journal of Forestry 99 (7):14-20.
Ruiz Pérez, M., M. Maoyi, B. Belcher, X. Yang, B. Mertens, L. Hua, and X. Jinzhong. 2009. The socio-economic and environmental roles of bamboo in rural China. Pages 267-286 in A. Ken-ichi and J. E. Nickum, editors. Good earths: regional and historical insights into China's environment. Kyoto University Press, Kyoto, Japan \& Trans Pacific Press, Melbourne, Australia.

Ruiz Pérez, M; M. Zhong, B. Belcher, C. Xie, M. Fu, and J. Xie. 1999. The role of bamboo plantations in rural development: the case of Anji County, Zhejiang, China. World Development 27 (1):101-104.

Song, Y., J. W. Burch, G. Geballe, and L. Geng. 1997. New organizational strategy for managing the forests of southeast China. The share holding integrated forestry tenure (SHIFT) system. Forest Ecology and Management 91:183-194. http://dx. doi.org/10.1016/S0378-1127(96)03891-1

$\mathrm{Su}$, D. 2013. Chinese bamboo and the construction of moral high ground by Song literati. Thesis, Master of Art Graduate Department of East Asian Studies, University of Toronto, Toronto, Ontario, Canada.

Tian Y., X. Li, G. Ma, and H. Hao. 2011. Impacts of the rising opportunity cost of farm labor on agricultural land use structure: theory and empirical evidences. Chinese Journal of Population Resources and Environment 9(1):85-90.

Tianhuangping Tourist Reception Centre. 2006. General planning of Tianhuangping's touristic area. Anji Bureau of LandscapeTourism Management, Anji, Zhejiang, China. (In Chinese).

United Nations Development Programme(UNDP)-China. 2010. China and a sustainable future: towards a low carbon economy and sustainable society. China human development report 2009/10. China Translation and Publishing Corporation, Beijing, China.

United Nations Statistical Division (UNSTAT). 2008. International standard industrial classification of all economic activities (ISIC), Rev. 4. UN Statistical Papers, Series M, No. 4, Rev. 4. United Nations, New York, New York, USA. [online] URL: http://unstats.un.org/unsd/publication/seriesM/seriesm 4rev4e. pdf

United Nations World Tourism Organization (UNWTO). 2013. UNWTO tourism highlights. 2013 edition. United Nations World Tourism Organization, Madrid, Spain.

Wang, C., and U. Chokkalingam. 2006. National overview. Pages 7-68 in U. Chokkalingam, Z. Zhou, C. Wang and T. Takeshi, editors. Learning lessons from China's forest rehabilitation efforts. National level review and special focus on Guangdong Province. CIFOR, Bogor, Indonesia.

Wang, F., and Q. Li. 2006. Analysis of tourist resources embedded within the Chinese bamboo culture (zhongguo zhu wenhua lvyou ziyuan jiexi). Beijing dier waiguoyu xueyuan xuebao [Journal of Beijing International Studies University] 133(3):67-75. (In Chinese)

Wang, P. 2001. A survey of the origin and feature of bamboo worship of southern minorities (nanfang shaoshu minzu zhu chongbai de qiyuan ji tezheng). Hubei minzu xueyuan xuebao (zhexue shehui kexue ban) [Journal of Hubei Institute for Nationalities (Philosophy and Social Sciences)] 19(4):21-25. (In Chinese) 
Wang, X. 2003. China in the eyes of Western travelers, 1860-1900. Pages 35-50 in A. A. Lew, L. Yu, J. Ap and G. Zhang, editors. Tourism in China. Haworth Press, Binghamton, New York, USA.

World Travel \& Tourism Council (WTTC). 2013. China. Travel $\&$ tourism economic impact 2013. World Travel and Tourism Council, London, UK.

Xie, J. Z. 2006. A comparative study of landuse changes and their environmental influences in China bamboo producing areas along an east-west gradient (zhongguo butong zhuchanqu tudi liyong bianhua dui shengtai huangjing yingxiang de bijiao yanjiu). $\mathrm{PhD}$ dissertation, Research Institute of Subtropical ForestryChinese Academy of Forestry,. Fuyang, Zhejiang, China. (In Chinese)

$\mathrm{Xu}$, J. 2011. China's new forests aren't as green as they seem. Nature 477(7365):371.

Xu, Q., P. Jiang, and Z. Xu. 2008. Soil microbial functional diversity under intensively managed bamboo plantations in southern China. Journal of Soils and Sediments 8:177-183. http:// dx.doi.org/10.1007/s11368-008-0007-3

Yan, E.R., X. H. Wang, J.J. Huang, G.Y. Li, and W. Zhou. 2008. Decline of soil nitrogen mineralization and nitrification during forest conversion of evergreen broad-leaved forest to plantations in the subtropical area of eastern China. Biogeochemistry 89:239-251. http://dx.doi.org/10.1007/s10533-008-9216-5

Yang, Y., C. Hui, and F. Du. 2010. China's bamboo: culture, resources, cultivation, utilization. INBAR, Beijing, China.

Yin, R. 1994. China's rural forestry since 1949. Journal of World Forest Resource Management 7(2):73-100.

Zhang, X. 2007. Function and benefits of bamboo ecotourism (zhulin shengtai lvyou de gongneng yu xiaoyi). Shijie zhuteng tongxun [World Bamboo and Rattan] 5(3):1-3. (In Chinese)

Zhao, L. 2002. Bamboo image in ancient Chinese literature (zhongguo gudai wenxue zhong de zhu yixiang). Luoyang gongxueyuan xuebao (shehui kexue ban) [Journal of Luoyang Institute of Technology (Social Science)] 20(3):65-67. (In Chinese)

Zhou, B., M. Fu, J. Xie, X. Yang, and Z. Li. 2005. Ecological functions of bamboo forest: research and application. Journal of Forestry Research 16(2):143-147.

Zhou, S. 2002. A grand hand to rebuild the scenic landscape (zaizao xiumei shanchuan de zhuangju). China Forestry Publishing House, Beijing, China. (In Chinese)

Zhu, S., N. Ma, and M. Fu. 1994. A compendium of Chinese bamboo. China Forestry Publishing House, Beijing, China.

Zou, F., and W. Liang. 2008. Study on the building bamboo tourist attractions with the bamboo culture (jianzao yunhan zhu wenhua de zhu lvyou jingguan yanjiu). Linye jingji wenti [Issues in Forestry Economics] 28(3):260-264. (In Chinese) 